\title{
Original article \\ Dexamethasone added to Bupivacaine prolongs the duration of analgesia for supraclavicular brachial plexus block \\ $\operatorname{Hoq} N^{1}$, Maruf $A A^{2}$
}

\begin{abstract}
:
Background: Local anaesthetics alone for supraclavicular brachial plexus block provide good operative conditions but have shorter duration of postoperative analgesia. Numerous adjuncts have been added to enhance the efficacy of the block. Steroids have anti-inflammatory as well as analgesic effects. Objectives: This study has been undertaken with a view to find out the efficacy of dexamethasone to increase the duration of analgesia when used as an adjuvant to bupivacaine in supraclavicular brachial plexus block in upper extremity surgery. Methods: Total 60 patients of ASA I and II undergoing upper extremity surgery under brachial plexus block were randomly divided into two equal groups of 30 each; Bupivacaine group- " $\mathrm{A}$ " received $0.5 \%$ bupivacaine 2 $\mathrm{mg} / \mathrm{kg}$ with distilled water $15 \mathrm{ml}$ and Dexamethasone group- 'B" received $0.5 \%$ bupivacaine 2 $\mathrm{mg} / \mathrm{kg}$ with dexamethasone $(0.2 \mathrm{mg} / \mathrm{kg})$ with distilled water $15 \mathrm{ml}$. The duration of analgesia in the two groups were compared. Results: There was markedly prolonged duration of analgesia in dexamethasone group. The mean duration of analgesia in bupivacaine group was $455 \pm 17.09$ minutes, whereas in dexamethasone group it was $864.50 \pm 25.19$ minutes. The results were statistically highly significant. Conclusion: Dexamethasone when added to bupivacaine in brachial plexus block it results significantly prolonged duration of post-operative analgesia, which was significantly higher in comparison to bupivacaine when it is used alone.
\end{abstract}

Keywords: Brachial Plexus Block; Bupivacaine; Dexamethasone

Bangladesh Journal of Medical Science Vol. 17 No. 02 April'18. Page : 296-301 DOI: http://dx.doi.org/10.3329/bjms.v17i2.35887

\section{Introduction:}

Brachial Plexus block is a popular and widely employed regional nerve block technique for anaesthesia and post-operative analgesia for surgery of the upper extremity. Regional nerve block avoids the unwanted effects of the anaesthetic drugs used during general anaesthesia and the stress of laryngoscopy and tracheal intubation. Supraclavicular brachial plexus block via Winnies' approach $^{1}$ is a very popular mode of anaesthesia for various upper limb surgeries.

Local anaesthetics alone for supraclavicular brachial plexus block provide good operative conditions but have shorter duration of postoperative analgesia. A local anaesthetic alone provides analgesia for not more than 4-8 hrs. Now a day's different drugs like morphine, pethidine, tramadol, clonidine, dexmeditomidine, butorphanol, midazolam are commonly used along with local anesthetics to achieve quick, dense and prolonged block. ${ }^{2,3}$ Since Morphine, pethidine, butorphanol are associated withside effects like sedation, respiratory depression and psychomimmetic effects ${ }^{2,3}$ drugs with minimal side effects are always looked for. Steroids have anti-inflammatory as well as analgesic effects. They relieve pain by reducing inflammation and by blocking transmission in nociceptive c-fibres and suppressing ectopic neuronal discharge and it does not causes any respiratory depression. ${ }^{4,5,6,7}$ That is why Dexamethasone is selected as an adjuvant to bupivacaine in this study.

In this study, we investigated the efficacy of

1. Lt Col Naimul Hoq, Classified Specialist in Anaesthesiology, Department of Anaesthesia, CMH Dhaka

2. Col Abdullah Al Maruf, Classified Specialist in Anaesthesiology, Department of Anaesthesia, BGB Hospital, Pilkhana, Dhaka

Correspondence to: Lt Col Naimul Hoq, Classified Specialist in Anaesthesiology, Department of Anaesthesia, CMH Dhaka. Email: naim838@gmail.com 
dexamethasone to increase the duration of analgesia when used as an adjuvant to bupivacaine in supraclavicular brachial plexus block in upper extremity surgery.

\section{Materials and Methods:}

This prospective clinical study was conducted at department of anaesthesia CMH Dhaka from January 2017 to June 2017. After approval from departmental review board and obtaining patients written informed consent 60 patients of American Society of Anesthesiologists (ASA) physical status I or II, aged 18 to 65 years, undergoing elective or emergency orthopaedic surgeries of upper limb under supraclavicular brachial plexus block were enrolled in this study.

Patient with history of uncontrolled diabetes, coagulopathy, renal and liver diseases, circulatory instability, cardio-vascular diseases, pregnant women, peptic ulcer disease, those with known allergy to local anaesthetics or dexamethasone and on long term steroid therapy were excluded from this study.

On arrival to the operating room, multi-parameter monitor was attached and the initial pulse, BP, respiratory rate, $\mathrm{SpO}_{2}$ was recorded as pre-block values. A 20 gauge IV cannula was inserted in a peripheral vein in the contralateral arm.

Patients were randomly divided into two equal groups of 30 each. Group-A received $0.5 \%$ bupivacaine $2 \mathrm{mg} / \mathrm{kg}$ with distilled water $15 \mathrm{ml}$ and group-B received $0.5 \%$ bupivacaine $2 \mathrm{mg} / \mathrm{kg}$ with dexamethasone $(0.2 \mathrm{mg} / \mathrm{kg})$ with distilled water $15 \mathrm{ml}$. The supraclavicular brachial plexus block was performed on the side of surgery in the supine position with the head turned to the opposite side and the arm placed medially towards the body after strict aseptic and antiseptic precautions. About $1.5 \mathrm{~cm}$ above the mid-clavicular point, a $22 \mathrm{G}, 1.5$ inches short beveled needle was introduced and directed just lateral to subclavian artery pulsation in caudad backward and medial direction until paresthesia was elicited over the hand. Keeping the needle in the same position, solution was injected slowly and ruling out intravascular injection intermittently by frequent aspiration through the syringe in between. The time of block performed was noted. The onset of sensory block was assessed with application of cold spirit swabs and by response to atraumatic prick with the blunt needle in different areas, onset time was defined as dull sensation along any of the nerve distribution; the time when sensory blockade achieved was noted. The surgery was allowed to proceed when complete anaesthesia was achieved. Intra-operatively patients were monitored for vital parameters like pulse, BP, respiratory rate and $\mathrm{SpO}_{2}$ at regular intervals. The duration of surgery in each case was noted.

Postoperative follow up was carried out in the recovery and postoperative ward. The duration of analgesia was noted according to the $0-10$ visual analogue scale (VAS) for pain at every hour. VAS score 0 and 8-10 were taken as no pain and worst pain perceived, respectively. The duration of analgesia was determined till the existence of good analgesia. When the patient began to experience the worst pain $(\mathrm{VAS}=8-10)$, it was considered that the analgesic action of the drugs is terminated and the time was noted. Patients were then rescued with additional analgesics on demand.

None of the patients were routinely sedated or given extra analgesics; until they started complain of pain. If any side effects related to the technique or drug such as nausea, vomiting, respiratory depression, pneumothorax occurred they were recorded and treated accordingly.

All the variables were expressed as mean $\pm \mathrm{SD}$; student t-test was done as the test of significance. The statistical analysis was done by using Graph pad software. P-value $<0.05$ was considered as statistically significant.

\section{Results:}

Patient's demographics data and duration of surgery were shown in Table-I.

No statistical significant differences were found between the two study groups.

Distributions of location of surgery in two study groups were also similar.(Table-2)

ASA status distributions in two study groups were also similar (Table-3)

The mean amount of bupivacaine used in group-A was $121 \pm 14.68 \mathrm{mg}$ and $125 \pm 15.09 \mathrm{mg}$ in group-B. This was not significant statistically.(Table-4)

The mean duration of analgesia in group-A was 455 \pm 17.09 minutes, whereas in group-B it was 864.50 \pm 25.19 minutes. This showed significant statistical difference (Table-5)

Vital parameters like pulse rate, blood pressure, respiratory rate and arterial oxygen saturation values were similar in both the groups and did not show any 
significant fluctuation.

No significant side effects like respiratory depression, preumothorax, signs/symptoms of LA toxicity or neurological sequalae were observed in any of the two groups. One case of tachycardia in group-A and two cases of tachycardia in group-B, and two cases of nausea in group-A and one case in group- $\mathrm{B}$ were observed which subsided without any further intervention. Three patients in group-A and three patients in group-B failed to achieve satisfactory levels of anaesthesia and required induction of general anaesthesia(Table-6)

\section{Discussion:}

Supraclavicular Brachial plexus block provide anaesthesia of the entire upper extremity in the most consistent manner of any brachial plexus techniques. It is the most effective block for all portions of the upper extremity and is carried out at the "division" level of the brachial plexus ${ }^{8}$ with high volume the trunk level of the plexus may also be blocked in this approach.

Currently available local anaesthetics can provide analgesia for limited period of time when used as single injection. Plain bupivacaine used by this method has been claimed to produce the block as long as 3-8 hours. ${ }^{9}{ }^{10}$ To extend the analgesia period beyond the operation rooms, various methods have been tried with the aim of prolonging the local anaesthetic action, like continuous infusion of local anaesthetics via indwelling catheters, use of different additive in local anaesthetics ${ }^{11,12,13,}$. Steroids are very potent anti-inflammatory and immunosuppressive agents. Perineural injection of steroidis reported to influence post-operative analgesia. Epidural steroids were used for treatment of back pain and sciatica. ${ }^{14}$, ${ }^{15}$ Various steroids has been used for this purpose, but dexamethasone a $9 \alpha$-derivative synthetic glucocorticoid is preferred because of its highly potent anti- inflammatory property, about 25-30 times as potent as hydrocortisone and without any mineralocorticoid activity thus was found to be safer and devoid of potential side effects. When steroid alone is used in regional blocks, the blockade is not produced. Steroids might bring about this effect by altering the function of potassium channels in the excitable cells ${ }^{16,17}$

In this study the patient characteristics (age, weight and sex) and duration of surgery were similar in two groups (Table-1). The anatomical location of surgery was classified into elbow, forearm, wrist and hand areas. Distributions of location of surgery in two study groups were similar (Table-2).ASA status distributions in two study groups were also similar (Table-3). In this study, the dose range of drug was determined according to the previous experiences of workers in different study ${ }^{18,19}$ and that was within the range of safe clinical dosage. The mean amount of bupivacaine used in group-A was $121 \pm 14.68$ $\mathrm{mg}$ and $125 \pm 15.09 \mathrm{mg}$ in group-B which was not significant statistically (Table-4)

In this study total duration of analgesia was determined by the intolerable pain (VAS, 8-10) and when patient demanded for analgesics. This was regarded as the end point for total analgesia period which was assessed hourly by the observer blinded to the study. Mild and moderate tolerable pain before pain VAS score 8 not needing rescue analgesics continued to contribute in VAS scoring till the end point. It has been found that in this study the total duration of analgesia following the brachial plexus block in the group-B was significantly higher than group-A. The mean duration of analgesia in group-A was $455 \pm 17.09$ minutes, whereas in group-B it was $864.50 \pm 25.19$ minutes this showed significant statistical difference(Table-5)

The block prolonging effect of dexamethasone was also found into following similar studies-Shrestha BR et al. ${ }^{18}$ carried out a study on supraclavicular brachial plexus block in 2007 with tramadol or dexamethasone as an admixture to bupivacaine in upper extremity surgery in 2007 and they reported that the total duration of analgesia was $453.17 \pm$ 72.81 minutes in tramadol group and $1028.17 \pm$ 194.51 minutes in steroid group.

Shrestha BR; Maharjan SK; Tabedar S. ${ }^{19}$ conducted a study on 2003 to compare the analgesic efficacy of local aesthetic with and without dexamethasone in supraclavicular brachial plexus block. There was significant prolonged duration of analgesia in the dexamethasone group than in the other group. Total duration of analgesia was $12.75 \pm 5.33$ hours in dexamethasone group compared to $3.16 \pm 0.48$ hours in without dexamethasone group. They concluded that addition of dexamethasone for brachial plexus block significantly prolongs the duration of analgesia. Three patients in group-Aand three patients in group-B approximately $10 \%$ of the patients in this study failed to achieve satisfactory levels of anaesthesia 
Dexamethasone added to Bupivacaine prolongs the duration of analgesia for supraclavicular brachial plexus block

and required induction of general anaesthesia (Table-6) This incidence of failure is comparable to an incidence that has been reported in some previous studies on various local anaesthetics. ${ }^{18,19}$

\section{Conclusion:}

Dexamethasone when added to bupivacaine in supraclavicular brachial plexus block it results significantly prolonged duration of post-operative analgesia, which was significantly higher in comparison with bupivacaine, when bupivacaine is used alone as local anaesthetic. This helps to minimize the cost and provides patient comfort. Such technique will be useful to be employed in our part of world where one has to face short of drugs and equipment's while providing anaesthetic services.

\section{Acknowledgements:}

Our special thanks to all participants in this study, hospital authority and pertinent staff for their support and cooperation.

Conflict of interest:

The authors have no conflict of interest.

Table- I: Patient's demographic data and duration of surgery

\begin{tabular}{llll}
\hline & $\begin{array}{l}\text { Group-A } \\
(\mathrm{n}=30)\end{array}$ & $\begin{array}{l}\text { Group-B } \\
(\mathrm{n}=30)\end{array}$ & P value \\
\hline Age (years) & $37.50 \pm 14.07$ & $33.66 \pm 13.68$ & 0.5073 \\
Sex (M/F) & $19 / 11$ & $20 / 10$ & \\
Weight (kg) & $60.30 \pm 7.64$ & $62.50 \pm 7.54$ & 0.5254 \\
Duration of surgery (min) & $129.5 \pm 20.33$ & $158.5 \pm 43.84$ & 0.0737 \\
\hline
\end{tabular}

Values were expressed as Mean $\pm \mathrm{SD}$, values are regarded significant if $\mathrm{P}$-value $<0.05$ There was no significant changes between the groups.

Table- 2: Anatomical sites of surgical intervention

\begin{tabular}{lllll}
\hline Sites & $\begin{array}{l}\text { Group-A }(\dagger) \\
(\mathrm{n}=30)\end{array}$ & $\begin{array}{l}\text { Group-B }(\dagger) \\
(\mathrm{n}=30)\end{array}$ & $\begin{array}{l}\text { Group-A (¥) } \\
100\end{array}$ & $\begin{array}{l}\text { Group-B (¥) } \\
\text { Arm }\end{array}$ \\
\hline Forearm & 10 & 12 & $33.33 \%$ & $40 \%$ \\
Wrist & 02 & 12 & $50 \%$ & $40 \%$ \\
Hand & 03 & 03 & $6.67 \%$ & $10 \%$ \\
\hline
\end{tabular}

Values were expressed as Frequency $(\dagger)$ and percentage (¥)

Table- 3: ASA Status Distribution

\begin{tabular}{lllll}
\hline Characteristic & $\begin{array}{l}\text { Group-A }(\dagger) \\
(\mathrm{n}=30)\end{array}$ & $\begin{array}{l}\text { Group-B }(\dagger) \\
(\mathrm{n}=30)\end{array}$ & $\begin{array}{l}\text { Group-A (¥) } \\
100\end{array}$ & $\begin{array}{l}\text { Group-B (¥) } \\
100\end{array}$ \\
\hline ASA-I & 23 & 22 & $76.67 \%$ & $73.33 \%$ \\
ASA-II & 07 & 08 & $23.33 \%$ & $26.67 \%$ \\
\hline
\end{tabular}

Values were expressed as Frequency (†) and percentage (¥) 
Table- 4: Amount of Bupivacaine

\begin{tabular}{llll}
\hline Parameter & $\begin{array}{l}\text { Group-A } \\
(\mathbf{n}=30)\end{array}$ & $\begin{array}{l}\text { Group-B } \\
(\mathbf{n}=\mathbf{3 0})\end{array}$ & P value \\
\hline
\end{tabular}

Amount of

Bupivacaine (mg)

$121 \pm 14.68 \quad 125 \pm 15.09$

0.5555

Values were expressed as Mean $\pm \mathrm{SD}$, values are regarded significant if $\mathrm{P}$-value $<0.05$ There was no significant changes between the groups.

Table- 5: Duration of Analgesia

\begin{tabular}{llll}
\hline Parameter & $\begin{array}{l}\text { Group-A } \\
(\mathbf{n = 3 0 )}\end{array}$ & $\begin{array}{l}\text { Group-B } \\
(\mathbf{n = 3 0 )}\end{array}$ & P value \\
\hline $\begin{array}{l}\text { Total Duration of } \\
\text { Analgesia (min) }\end{array}$ & $455 \pm 17.09$ & $864.5 \pm 25.19$ & $<0.0001$ \\
\hline
\end{tabular}

Values were expressed as Mean $\pm \mathrm{SD}$, values are regarded significant if $\mathrm{P}$-value $<0.05$ There was significant changes between the groups.

Table- 6: Complications

\begin{tabular}{lcccc}
\hline Characteristic Group-A (†) & Group-B (†) & Group-A (¥) & Group-B (¥) \\
\hline Nausea & 02 & 01 & $6.67 \%$ & $3.33 \%$ \\
Tachycardia & 01 & 02 & $3.33 \%$ & $6.67 \%$ \\
Failed block & 03 & 03 & $10 \%$ & $10 \%$
\end{tabular}

Values were expressed as Frequency $(\dagger)$ and percentage $(¥)$ 
Dexamethasone added to Bupivacaine prolongs the duration of analgesia for supraclavicular brachial plexus block

\section{References:}

1. Winnie A.P., Collins V.J., The subclavian perivascular technique of brachial plexus anaesthesia. Anaesthesiology 1964; 25: 353

2. Bazin J.E., Massoni C., Bruelle P., Fenies V., Groslier D., Schoeffler P., The addition of opioids to local anaesthetics in Brachial Plexus block: the comparative effects of morphine, buprenorphine and sufentanil. Anaesthesia 1997; 52:858-62

3. Chattopadhyay S., Mitra LG., Tramadol as an adjuvant for Brachial Plexus block. J Anaesth Clin Pharmacol 2007; 23(2):187-9.

4. M.P Golwala, V.N Swadia, et al; Pain Relief by Dexamethasone as an Adjuvant to Local Anaesthetics in Supraclavicular Brachial Plexus Block; $J$ AnaesthclinPharmacol 2009;25(3):285-288

5. Johanson A., Hao J., Local corticosteroid application blocks transmission in normal nociceptive c-fibres. Acta Anesthesiologicascand 1990; 34:335-8.

6. Kopacz D.J, Lacouture P.G., Wu D., et al; The dose response and effects of dexamethasone on bupivacine microcapsules for intercostals blockade in healthy volunteers. AnaesthAnalg 2003; 96:576-82

7. Baxendale BR, Vater M, Lavery KM: Dexamethasone reduces pain and swelling following extraction of third molar teeth. Anaesthesia 1993; 48; 961-964.

8. Lanz E., Theiss D., Jankovic D., The extent of blockade following various techniques of brachial plexus block. Anesth Analg 1983; 62: 55 - 58.

9. De Jong RH; Wagman IH. Physiological mechanism of peripheral nerve block by local anaesthetics. Anaesthesiology 1963; 24: 684-687.
10. Winnie AP, Tay CH, Patel KP, Ramamurthy S, Durrani Z. Pharmacokinetics of local anaesthetics during Brachial Plexus blocks. Anaesth Analg 1977; 56:852-61.

11. KojJarbo, Yatindra KB, Nidhi BP. Brachial Plexus block with midazolam and bupivacaine improves analgesia. Can J Anaesth 2005; 52(8):822-6.

12. Robaux S., Blunt C., Viel E., et al., Tramadol added to 1.5\% Mepivaciane for axillary Brachial Plexus block improves postoperative analgesia. Anaesth Analg 2004 April; 98(4):1172-7.

13. Ali M, Mehran R, et al; Dexamethasone added to lidocaine prolongs axillary brachial plexus blocked. Anaesth Analg 2006;102:263-7

14. Honorio T. Benzon, Epidural steroids. In P.Prithvi Raj. Pain medicine, a comprehensive review. Mosby publications 1999: 259-263.

15. Wang YL, Tan PP, Yang CH: Epidural dexamethasone reduces the incidence of back ache after lumbar epidural anaesthesia. Anaesth. Analg 1997; 84; 376-78

16. Attali B., Latter H., Rachamim N., Garty H. A corticosteroid-induced gene expressing an "IsKlike" $\mathrm{K}+$ channel activity in Xenopus oocytes. ProcNatlAcadSci USA 1995; 92:6092-6

17. Takimoto K., Levitan E.S. Glucocorticoid induction of $\mathrm{Kv} 1.5 \mathrm{~K}+$ channel gene expression in ventricle of rat heart. Circ Res 1994; 75:1006-13

18. Shrestha BR, Maharjan SK, Gautam B, Joshi MR: Comparative study between tramadol and dexamethasone as an admixture to bupivacaine in supraclavicular brachial plexus block. J Nepal Med Assoc. 2007; 46(168): 158-64

19. Shrestha BR, Maharjan SK, Tabedar S; Supraclavicular brachial plexus block with and without dexamethasone-A comparative study. Kathmandu University Medical journal 2003; 1(3):158-160 